\title{
Assessment of service satisfaction and associated status among women who have given birth in Adigrat general hospital, Ethiopia, 2018.
}

Teferi Gebru Gebremeskel ( $\square$ teferigebru12@gmail.com )

Aksum university

Desta Tukue

Adigrat University

Lemlem Gebremariam

Adigrat University

Hirut Teame

Adigrat University

\section{Research}

Keywords: service delivery, satisfaction, women who gave birth

Posted Date: April 7th, 2020

DOI: https://doi.org/10.21203/rs.3.rs-19454/v1

License: (c) (i) This work is licensed under a Creative Commons Attribution 4.0 International License. Read Full License 


\section{Abstract}

Background: The study aimed to assess the satisfaction of service delivery and the associated status among women who gave birth to Adigrat general hospital, Ethiopia, 2018.

Methods: Institutional based cross-sectional study design was conducted in Adigrat hospital from February to March 2018. Interviews with interviewed using structured questionnaires of 302 systematic women who were born at general hospital. The information is submitted to EPI-info version 7.2 and exported to SPSS version 20 for analysis. Summary statistics and logistic regression analyses were performed. OR with two-sided $95 \% \mathrm{Cl}$ and P-value $<0.05$ were used to identify the factors associated with the service satisfaction.

Result: Maternal satisfaction in labor and delivery was70.2\%. Women living in rural areas were $98.8 \%$ times less likely to be satisfied with service delivery than those living in urban area (AOR: $0.012,95 \% \mathrm{Cl}$ $(0.002,0.065)$. women who plan to give birth at the hospital have more than forty times more than their referrals for maternity service (AOR: $40.43,95 \% \mathrm{Cl}(2.75,595.23)$ ).

Conclusion: The overall share of mothers who were satisfied with the service they provided was appropriate. As a city resident and the reason for delivering in the hospital are related to service satisfaction. Therefore the staff of the hospital has a continuing education and personal relationship. The care giver must fully understand the value of their care and provided care that is in line with those expectations.

\section{Plain English Summary}

The extent of service satisfaction will have immediate and long effects on women's health and later use of the service. Augmented service satisfaction can increase if care is provided. The current study provides precise information about the satisfaction of service delivery and the factors influencing them. This study will be used institutional based cross-sectional study design. The findings of the overall share of mothers who were satisfied with the service they provided were appropriate. As a city resident and the reason for delivering in the hospital are related to service satisfaction. Therefore the staff of the hospital has a continuing education and personal relationship. The care giver must fully understand the value of their care and provided care that is in line with those expectations.

\section{Background}

Pregnancy Associate in Nursing birthing claim the lives of a calculable [ $\left.{ }^{*} \mathrm{fr} 1\right]$ 1,000,000 ladies globally every year. quite half these deaths occur in Africa ${ }^{(1,2)}$. Ethiopia is one amongst the countries that have the very best maternal mortality rates (MMR) within the world that is calculable to be $412 / 100,000$ live births ${ }^{(3,4)}$. A part of the mortality is attributed to poor delivery care ${ }^{(3)}$. Labor may be a time of women's distinctive sensitivity to environmental factors. Events thus the land also the\} interactions occurring throughout labor have powerful psychological effects; therefore a positive birthing expertise is 
fascinating for the advantage of each the parturient lady and her kid. Studies have additionally confirmed that the intrapartum and postnatal nurses or midwives have usually been the deciding issue of whether or

not the girl features a positive or negative expertise throughout childbirth ${ }^{(5,6)}$. A woman's satisfaction with the delivery service could have immediate and long effects on her health and ulterior utilization of the services. Providing satisfying delivery care will increase service utilization ${ }^{(3)}$. Mother satisfaction may be a primary suggests that of measure the effectiveness of provision. However, the inadequate discovery of their wants could end in patient discontentment. Patient's perception of service quality shapes their confidence regarding the utilization of the obtainable health care facility. the explanations for measure patient satisfaction embody describing health care service from the patient's perspective, activity of the method of care and analysis of care as a perform of patient satisfaction ${ }^{(5)}$.

Satisfaction may be a important output indicator of quality health care. Satisfaction throughout birthing is vital for the mother and baby health. In Ethiopia, efforts are being created to form health establishments client-oriented. However, the proof remains inadequate from the patient's perspective. The World Health Organization emphasizes the analysis of the structure, procedure, and outcome of health services to boost the standard of care. rising facility-based care may be a vital necessity nonetheless no wide applicable, effective methodology presently exists ${ }^{(7)}$. Most of the 350,000 maternal deaths, $1 \cdot 2$ million intrapartum-related stillbirths, and 3.1 million babe deaths that occur every year can be avoided through the delivery is related to poor service provided throughout labor and delivery ${ }^{(8)}$. The discontentment of mothers laboring and delivery service in health establishments will cause home delivery and maternal mortality within the case of home delivery. Poor quality of care is one amongst the conducive factors of maternal morbidity and death rate ${ }^{(5)}$.

Neonatal outcomes ar inextricably connected to maternal health and, therefore, to the standard of care a mother receives throughout labor, delivery and within the immediate postnatal amount that is that the highest risk amount for each mothers and babies. the explanations forwarded by researchers for the upper maternal mortality and lower coverage of skilful delivery are related to poor service provided throughout labor and delivery ${ }^{(8,9)}$.

\section{Methods}

This Institutional-based cross-sectional study will be conducted from February 2018 to March 2019 among mothers who attended labor and delivery service. The study was conducted in Adigrat general hospital, which is located in the city of Adigrat, Tigray Region (North Ethiopia). It provides a broad range of medical services to both in and out patients.

The source population for the study was all women who attend Hospitals for delivery service in Adigrat Hospital. The study population was all mothers who gave birth in Adigrat Hospitals and full fill the selection criteria. 
Mothers who were attend delivery services in Adigrat Hospitals and willing to participate in the study period. Whereas mothers who weren't mentally competent or WHO had any psychiatrically disorders and critically sick throughout information assortment were excluded.

The sample size was 302 determined by using single population proportion formula considering: the $5 \%$ a margin of error, $95 \%$ confidence interval, the proportion of satisfaction in labor and delivery service was $74.9 \%{ }^{(10)}$, and adding $5 \%$ non-response rate. A systematic sampling method was used on women who gave birth during data collection time.

Mother's satisfaction: Mothers gain satisfaction during labor and delivery service. Assessment: Assess mothers their level of satisfaction in labor and delivery service.

Data was collected by victimization associate degree interviewer-administered and structured form custom-made from totally different similar analysis $(10,12,13)$ with modification in step with the context of the study space. to ascertain face validity and translation quality the form was tested on thirty ladies the study space by knowledge collectors and supervisors throughout coaching. Some queries, language clarity and data were revised and also the form was finalized for the study. The form includes sociodemographic, generative history, Institutional, and supply of data connected factors.

Five health care provider satisfaction collectors and 2 supervisors were recruited from the sanatorium and that they got coaching for sooner or later. The supervisors followed the method of satisfaction assortment daily, checked the info completeness consistency and communicate with principal investigators daily.

Data were coded, cleaned, recorded and entered EPI data 7and finally export to SPSS version twenty two.00 for analysis. Straight forward descriptive outline statistics were done. Tables, statements, charts, and graphs were wont to gift the results of the analyzed information. Variables that had $p<0.2$ on quantity analysis were entered multivariable supply multivariate analysis. once checking victimisation chi-square take a look at variables with tiny cell size were unified into connected classes. applicable model medical specialty and goodness of match tests were done. multiple correlation was checked \{to take a look at|to check\} correlation among predictor variables and Hosmer and Lemeshow test P-value $(>0.2)$ were conducted to envision model fitness. The applied math association between the various freelance variables concerning dependent was measured victimisation $\mathrm{OR}, \mathrm{AOR}$, ninety fifth $\mathrm{Cl}$ and $\mathrm{P}$ values $<0.05$ was thought of statistically important.

\section{Results}

\section{Socio-demographic characteristics}

A total of 302 delivering mothers participated in the response rate of $100 \%$. Married women respondents were $77.8 \%$ and the total family size one up to three was $61.9 \%$. The majority of the respondents were with an age range of 26-35 years. More than half (66.6\%) of participants were urban residence. (Table 1). 


\section{Obstetric characteristics of mothers}

Two third of (55.8\%) the mothers had a parity of 2-5 times. History's previous facility delivery was $63.2 \%$ and wanted the status of pregnancy was $69.9 \%$. Concerning reasons to deliver in the hospital, $68.5 \%$ were planned. Spontaneous vaginal delivery of the respondents was $47.4 \%$ and alive fetal outcome was $93.4 \%$ (Table2).

\section{Mother's satisfaction related characteristics}

The proportion of mothers who reported privacy during the physical examination was $62.9 \%$. Most of the respondents $(77.5 \%)$ were satisfied with toilet cleanness and availability. The drug's availability has a large number of satisfied mothers (63.2\%). (Table 3$)$.

\section{Care providers related characteristics}

Waiting for a doctor or a nurse to 30 minutes was $38.7 \%$. Shouting or using abusive language by the health professional to the mothers was $36.8 \%$. The majority of the respondent (63.6\%) feel comfortable or free to discuss all their concerns to the provider and recommendations to use hospitals were $64.2 \%$ (table 4).

\section{Prevalence of maternal satisfaction in delivery service and associated factors:}

In the study, the overall prevalence of the delivery service satisfaction rate was $70.2 \%$. In binary logistic regression: residency, the reason to deliver in this hospital, previous delivery service at this hospital, availability of cleanness toilet, the approach of clinicians (friendly care), availability of waiting area, mode of delivery and clinicians way of examination were significantly associated with service delivery satisfaction in Adigrat general hospital. Significant variables in the binary logistic regression were entered into multivariate logistic regression and in the multivariate logistic regression rural residency, planned reason to deliver in the hospital had significant association with service delivery satisfaction with AOR: 0.012 95\% Cl: $(0.002,0.065)$, AOR: $40.43,95 \%$ Cl: $(2.75,595.23)$ respectively (Table 5).

\section{Discussion}

Mother satisfaction is a primary means of measuring the effectiveness of healthcare delivery. Patients have explicit desires for quality services when they visit health institutions. However, the inadequate discovery of their needs may result in patient dissatisfaction. Patient's perception of service quality shapes their confidence about the use of the available health care facility. The reasons for measuring 
patient satisfaction include describing health care service from the patient's perspective, measurement of the process of care and evaluation of care as a function of patient satisfaction ${ }^{(5)}$.

In this study, the overall satisfaction of mothers on labor and delivery service was found to be $70.2 \%$. This is lower than studies conducted in Mid-Western Nepal (89.88\%), Felege Hiwot Referral Hospital Northwest Ethiopia (74.9\%), Wolayita zone, Ethiopia (82.9\%), Jimma (77\%) and Assela Hospital (80.7\%), Debre Markos town, Ethiopia (81.7\%), Mekelle, Ethiopia (79.7\%), Abrade Swede Memorial Primary Hospital, Ethiopia (88\%) and Arbaminch District Southern Ethiopia (90.2\%). ${ }^{(11-19) . ~ H o w e v e r, ~ t h i s ~ f i n d i n g ~ i s ~ h i g h e r ~}$ than the study conduct in Amhara Referral Hospitals, Ethiopia (61.9\%), in Ethiopia and South Africa (51.9\%) and Nairobi Kenya (56\%) ${ }^{(20-22)}$. The difference with the above finding could be explained by a real difference in the quality of services provided an expectation of mothers or the type of health facilities $(9)$.

Among the respondent, the odd of mother's satisfaction on labor and delivery service among those with the place of residence in a rural area were $99.9 \%$ less likely to satisfy at $95 \% \mathrm{Cl}(0.002,0.065)$ than those with the urban residence. This finding inconsistency with study conduct in Wolaita Zone, Ethiopia, $2018^{(13)}$, Tshwane, South Africa, 2017(23). Thus, this may be due to women's various expectations about hospital labor and delivery. These expectations were based on their own past experiences in hospital facility experiences of friends and relations in a hospital facility, myths about procedures in the hospital and societal values and based WHO standard of care framework ${ }^{(16,24)}$.

In this study, the result showed that the odds of mothers' satisfaction on labor and delivery service among those who had planned reason to deliver in the hospital were 40 times more likely satisfy than those who had referral reason to deliver in the hospital.

The result of this study also showed that most of the delivering mothers were very likely to recommend the facility to friends, family, and for themselves (57\%) and $64.2 \%$ ) respectively. Limitation of the study only focuses on the mothers who get delivery service but factors related to the readiness and quality health facility service should be assessed. Measuring the mother's satisfaction using a qualitative study will be better.

\section{Conclusions}

The overall proportion of mothers who were satisfied with the labor and delivery service provided was suboptimal. The study strongly suggests that the services provided can be more patient-centered.

Maternal satisfaction during this period is predicted by the urban residence and planned reason to deliver in the hospital. From this finding, it is recommended that the issue should also need to be assessed from different community group's perspectives i.e. care providers and community leaders who understand the situation in a better way and design interventional activities accordingly, the staff of the Hospital should have continuous education and interpersonal relationship, caregivers need to fully understand the expectations that pediment has for their care and provide care that is consistent with those expectations 
and further studies should be conducted in the hospital and outside the hospital set up and in different parts of the country to come up with more representative findings.

\section{Declarations}

\section{Ethics approval and consent to participant}

Ethical clearance was obtained from the Ethical Review Board of ADU, College of Medicine and Health Sciences and it is also got granted from the Health office of Adigrat hospital. Verbal consent from pregnant women of study subjects was obtained and the objective of the study was explained to them. Privacy and confidentiality of collected information were ensured at all levels.

\section{Consent for publication}

Not applicable

\section{Availability of data and materials}

The datasets used during the current study available from the corresponding author on reasonable request.

\section{Computing interest}

The authors declare that they have no competing interests

\section{Funding}

This research project is no funded.

\section{Authors' contributions}

TG designed the study, performed the statistical analysis, drafted the paper. DT, LG, and HT data analysis and read and approved the final paper.

\section{Acknowledgments}

We are highly indebted to all participants of the study, data collectors and supervisors for their worthy efforts and participation in this study. We are also thankful for the administrative bodies of Adigrat 
general hospitals at all levels who endorsed us to undertake this study.

\section{Authors' information}

Teferi Gebru Gebremeskel (MPH-RH): Department of Reproductive Health, College of Health Sciences, Aksum University, Aksum, Ethiopia. Email: teferigebru12@gmail.com

Desta Tukue (Obstetrician and gynecologist in Adigrat General Hospital, Adigrat, Ethiopia) E-mail= dekulem2005@yahoo.com

Lemlem Gebremariam ((MPH-RH, assistant professor) college of Medicine and health sciences, Adigrat University, Adigrat, Ethiopia E-mail= lemgmed@yahoo.com.

Hirut Teame Gebru (MPH): Department of Public Health, College of Medicine and health sciences, Adigrat University, Adigrat, Ethiopia) hiruteame@gmail.com

\section{Abbreviations}

MDG-Millennium Development Goal; MMR-Maternal Mortality Ratio; SPSS-Statistical Package for Social Sciences; SVD -Spontaneous Vaginal Delivery; UNFPA-United Nation Population Fund; UNICEF-United Nations Children's Fund; UN-United Nation; WHO-World Health Organization; EDHS-Ethiopian Demographic And Health Survey; AIDS- Acquired Immune Deficiency Syndrome; HIV- Human Immune Deficiency Virus.

\section{References}

1. Colombia university Mailman school of public health spotlights on health and rights http://healthandrights.ccnmtl.columbia.edu/reproductive_health/causes_maternal_mortality.htm/

2. WHO, UNICEF, UNFPA, Bank W. Trends in Maternal Mortality. The World Bank and the United Nations Population Division Geneva. World Health Organization2014

3. Azmeraw Tayelgn, Desalegn T Zegeye and Yigzaw Kebede Mothers' satisfaction with referral hospital delivery service in Amhara Region, Ethiopia 2011

4. Federal Democratic Republic of Ethiopia Central Statistical Agency OM: EDHS 2016 Addis Ababa, Ethiopia

5. TadeleMelese, Yirgu Gebrehiwot, Daniel Bisetegne, and Dereje Habte Assessment of client satisfaction in labor and delivery services at a maternity referral hospital in Ethiopia2006

6. Atiya, K.M., 2016. Maternal satisfaction regarding the quality of nursing care during labor and delivery in Sulaimani teaching hospital. International Journal of Nursing and Midwifery, 8(3), pp.1827. 
7. Simbar M, Ghafari F, Tork Zahrani S, Alavi Majd H. Assessment of quality of midwifery care in labor and delivery wards of selected Kordestan Medical Science University hospitals. International journal of health care quality assurance. 2009 May 1;22(3):266-77.

8. Spector JM, Agrawal P, Kodkany B, Lipsitz S, Lashoher A, Dziekan G, Bahl R, Merialdi M, Mathai M, Lemer $C$, Gawande A. Improving the quality of care for maternal and newborn health: prospective pilot study of the WHO safe childbirth checklist program. PloS one. 2012 May 16;7(5):

9. Federal Democratic Republic of Ethiopia Central Statistical Agency OM: EDHS 2014 Addis Ababa, Ethiopia

10. Mekonnen ME, Yalew WA, Anteneh ZA. Women's satisfaction with childbirth care in Felege Hiwot Referral Hospital, Bahir Dar city, Northwest Ethiopia, 2014: a cross-sectional study. BMC research notes. 2015 Oct 1;8(1):528.

11. Asha Panth and Praveena Kafle (2018) Maternal Satisfaction on Delivery Service among Postnatal Mothers in a Government Hospital, Mid-Western Nepal, Hindawi Obstetrics and Gynecology International, 4530161.

12. Mekonnen, M. E., Yalew, W. A. \& Anteneh, Z. A. 2015. Women's satisfaction with childbirth care in Felege Hiwot Referral Hospital, Bahir Dar city, Northwest Ethiopia, 2014: a cross-sectional study. BMC research notes, 8, 528 .

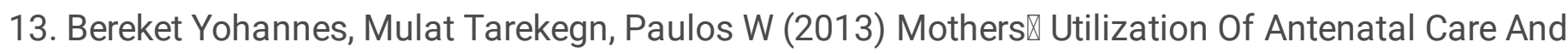
Their Satisfaction With Delivery Services In Selected Public Health Facilities Of Wolaita Zone, Southern Ethiopia. International Journal of Scientific \& Technology Research 2.

14. Alemayehu Kumsa, G T, A N, Kebede G (2016) Satisfaction with emergency obstetric and newborn care services among clients using public health facilities in Jimma Zone, Oromia Regional State, Ethiopia; a cross-sectional study. BMC Pregnancy and Childbirth 16.

15. Roza Amdemichael, Mesfin Tafa, Fekadu H (2014) Maternal Satisfaction with the Delivery Services in Assela Hospital, Arsi Zone, Oromia Region. Gynecology \& Obstetrics 4:8.

16. Bitew K, Ayichiluhm M, Yimam K (2015) Maternal satisfaction on delivery service and its associated factors among mothers who gave birth in public health facilities of Debremarkos town, northwest Ethiopia. BioMed Res Int, pp: 1-6.

17. Taklu Marama, Hinsermu Bayu, Mulualem Merga, Wakgari Binu (2018) Patient Satisfaction and Associated Factors among Clients Admitted to Obstetrics and Gynecology Wards of Public Hospitals in Mekelle Town, Ethiopia: An Institution-Based Cross-Sectional Study. Hindawi Obstetrics and Gynecology International 2018:9.

18. Gizew Dessie Asres(2018) Satisfaction and Associated Factors among Mothers Delivered at Asrade Zewude Memorial Primary Hospital, Bure, West Gojjam, Amhara, Ethiopia: A Cross-Sectional Stud, Primary Health Care: Open Access 8:2.

19. Deewana, Z. 2017. Quality of Delivery Service at Public Health Facilities in Arba Minch District, Gamo Gofa Zone, Southern Ethiopia. Journal of Gynecology and Obstetrics, 5, 31. 
20. Tayelgn A, Zegeye DT, Kebede Y (2011) Mothers' satisfaction with referral hospital delivery service in Amhara Region, Ethiopia. BMC Pregnancy Childbirth 11:78

21. Lumadiand TG, Buch E (2011) Patients' satisfaction with midwifery services in a regional hospital and its referring clinics in the Limpopo Province of South Africa. Afr J Nurs Midwifery 13: 14-28. 10.

22. Eva SB, Michael AK (2009) Women's satisfaction with delivery care in Nairobi's informal settlements. Intern J Qual Health Care 21: 79-86

23. Sarie J Oosthuizen, Anne-Marie Bergh, Robert C Pattinson, Jackie Grimbeek (2017) It does matter where you come from: mothers' experiences of childbirth in midwife obstetric units, Tshwane, South Africa. Reproductive health 14:151

24. Tunçalp Ö, Were WM, MacLennan C, Oladapo OT, Gulmezoglu AM, et al (2015) Quality of care for pregnant women and newborns-the WHO vision. BJOG. 122:1045-9

\section{Tables}

Table 1 socio-demographic characteristics of mothers get delivery service in Adigrat general hospital, 2018.

\begin{tabular}{|c|c|c|c|c|}
\hline s.no & Variable & category & Frequency & Percentage \\
\hline \multirow[t]{3}{*}{1.} & Age & $18-25$ & 118 & 39.1 \\
\hline & & $26-35$ & 147 & 48.7 \\
\hline & & $36-45$ & 37 & 12.3 \\
\hline \multirow[t]{4}{*}{2.} & Martial status & Married & 235 & 77.8 \\
\hline & & Single & 31 & 10.3 \\
\hline & & Divorced & 19 & 6.3 \\
\hline & & Widowed & 16 & 5.3 \\
\hline \multirow[t]{6}{*}{3.} & Occupation & Housewife & 109 & 36.1 \\
\hline & & Farmer & 48 & 15.9 \\
\hline & & Government employee & 54 & 17.9 \\
\hline & & Daily laborer & 6 & 2.0 \\
\hline & & Merchant & 54 & 17.9 \\
\hline & & Other & 31 & 10.3 \\
\hline \multirow[t]{4}{*}{4.} & Educational Status & Illiterate & 67 & 22.2 \\
\hline & & Read and write & 97 & 32.1 \\
\hline & & Primary Education & 58 & 19.2 \\
\hline & & High school and above & 74 & 24.5 \\
\hline \multirow[t]{2}{*}{5.} & Residence & Urban & 201 & 66.6 \\
\hline & & Rural & 101 & 33.4 \\
\hline \multirow[t]{3}{*}{6.} & Number of total family size & $1-3$ & 187 & 61.9 \\
\hline & & $4-6$ & 90 & 29.8 \\
\hline & & $>7$ & 25 & 8.3 \\
\hline
\end{tabular}

Table 2: Obstetric history of mothers get delivery service in adigrat general hospital, Adigrat2018 


\begin{tabular}{|c|c|c|c|}
\hline Variables & Response & Frequency & Percentage \\
\hline \multirow[t]{3}{*}{ Parity } & 1 & 98 & 32.6 \\
\hline & $2-5$ & 168 & 55.8 \\
\hline & $>6$ & 35 & 11.6 \\
\hline \multirow[t]{2}{*}{ Previous facility delivery } & Yes & 191 & 63.2 \\
\hline & No & 111 & 36.8 \\
\hline \multirow[t]{2}{*}{ Wanted status of pregnancy } & Wanted & 211 & 69.9 \\
\hline & Unwanted & 88 & 29.1 \\
\hline \multirow[t]{6}{*}{ ANC service } & First visit & 6 & 2.0 \\
\hline & Second visit & 33 & 10.9 \\
\hline & Third visit & 111 & 36.8 \\
\hline & Fourth visit & 67 & 22.2 \\
\hline & All visit & 73 & 24.2 \\
\hline & No visit & 12 & 4.0 \\
\hline \multirow{2}{*}{$\begin{array}{l}\text { Reasons } \\
\text { to deliver in this hospital }\end{array}$} & Planned & 207 & 68.5 \\
\hline & Referral & 95 & 31.5 \\
\hline \multirow[t]{3}{*}{ Mode of delivery } & Spontaneous vaginal delivery & 143 & 47.4 \\
\hline & Cesarean section & 94 & 31.1 \\
\hline & Instrumental delivery & 65 & 21.5 \\
\hline \multirow[t]{2}{*}{ Sex of newborn } & Male & 148 & 49.0 \\
\hline & Female & 154 & 51.0 \\
\hline \multirow[t]{2}{*}{ Fetal outcome } & Alive & 282 & 93.4 \\
\hline & Dead & 20 & 6.6 \\
\hline
\end{tabular}

Table 3: Mother's satisfaction related characteristics in adigrat general hospital, Adigrat2018 


\begin{tabular}{|c|c|c|c|}
\hline Variables & Category & Frequency & Percentage \\
\hline \multirow[t]{2}{*}{ Satisfaction with privacy } & Satisfied & 190 & 62.9 \\
\hline & Unsatisfied & 112 & 37.1 \\
\hline \multirow[t]{2}{*}{ Satisfaction with the gender of birth attendant } & Satisfied & 146 & 48.3 \\
\hline & Unsatisfied & 156 & 51.7 \\
\hline \multirow[t]{2}{*}{ Satisfaction with information service } & Satisfied & 129 & 42.7 \\
\hline & Unsatisfied & 173 & 57.3 \\
\hline \multirow[t]{2}{*}{ Satisfaction with courtesy and respect } & Satisfied & 153 & 50.7 \\
\hline & Unsatisfied & 149 & 49.3 \\
\hline \multirow[t]{2}{*}{ Satisfaction with the way of examination } & Satisfied & 199 & 65.9 \\
\hline & Unsatisfied & 103 & 34.1 \\
\hline \multirow{2}{*}{$\begin{array}{l}\text { Satisfaction with the assurance of confidentiality by the health } \\
\text { professional }\end{array}$} & Satisfied & 200 & 66.2 \\
\hline & Unsatisfied & 102 & 33.8 \\
\hline \multirow[t]{2}{*}{ Satisfaction with the care of delivery service } & Satisfied & 231 & 76.5 \\
\hline & Unsatisfied & 71 & 23.5 \\
\hline \multirow[t]{2}{*}{ Satisfaction level during labor service } & Satisfied & 234 & 77.5 \\
\hline & Unsatisfied & 68 & 22.5 \\
\hline \multirow[t]{2}{*}{ Satisfaction with woman-friendly care } & Satisfied & 224 & 74.2 \\
\hline & Unsatisfied & 78 & 25.8 \\
\hline \multirow[t]{2}{*}{ Satisfaction with toilet cleanness and availability } & Satisfied & 234 & 77.5 \\
\hline & Unsatisfied & 68 & 22.5 \\
\hline \multirow[t]{2}{*}{ Satisfaction with drugs availability } & Satisfied & 191 & 63.2 \\
\hline & Unsatisfied & 111 & 36.8 \\
\hline \multirow[t]{2}{*}{ Presence of waiting area } & Satisfied & 192 & 63.6 \\
\hline & Unsatisfied & 110 & 36.4 \\
\hline \multirow[t]{2}{*}{ Overall satisfaction labor and delivery service } & Satisfied & 212 & 70.2 \\
\hline & Unsatisfied & 90 & 29.8 \\
\hline \multirow[t]{2}{*}{ Cleanness of the couch } & Satisfied & 169 & 56.0 \\
\hline & Unsatisfied & 133 & 44.0 \\
\hline \multirow[t]{2}{*}{ Satisfaction with postnatal care } & Satisfied & 215 & 71.2 \\
\hline & Unsatisfied & 87 & 28.8 \\
\hline
\end{tabular}

Table 4: Care providers related characteristics of adigrat general hospital, 2018. 


\begin{tabular}{|c|c|c|c|}
\hline & 30 minutes & 117 & 38.7 \\
\hline & 1 hour & 84 & 27.8 \\
\hline & $>1$ hour & 25 & 8.3 \\
\hline \multirow{2}{*}{$\begin{array}{l}\text { Do any staff ever speak to you in a way that upset you? (e.g. Shouting or using abusive } \\
\text { language) }\end{array}$} & Yes & 111 & 36.8 \\
\hline & No & 191 & 63.2 \\
\hline \multirow[t]{2}{*}{ Feeling comfortable/free to discuss all your concerns with your provider? } & Yes & 192 & 63.6 \\
\hline & No & 110 & 36.4 \\
\hline \multirow[t]{2}{*}{ Recommend the hospital to their family or friends for delivery service } & Yes & 172 & 57.0 \\
\hline & No & 130 & 43.0 \\
\hline \multirow[t]{2}{*}{ Hospital use recommended for you } & Yes & 194 & 64.2 \\
\hline & No & 108 & 35.8 \\
\hline
\end{tabular}

Table 5: factors associated with delivery service satisfaction among mothers in Adigrat general hospital, May 2018(n=302).

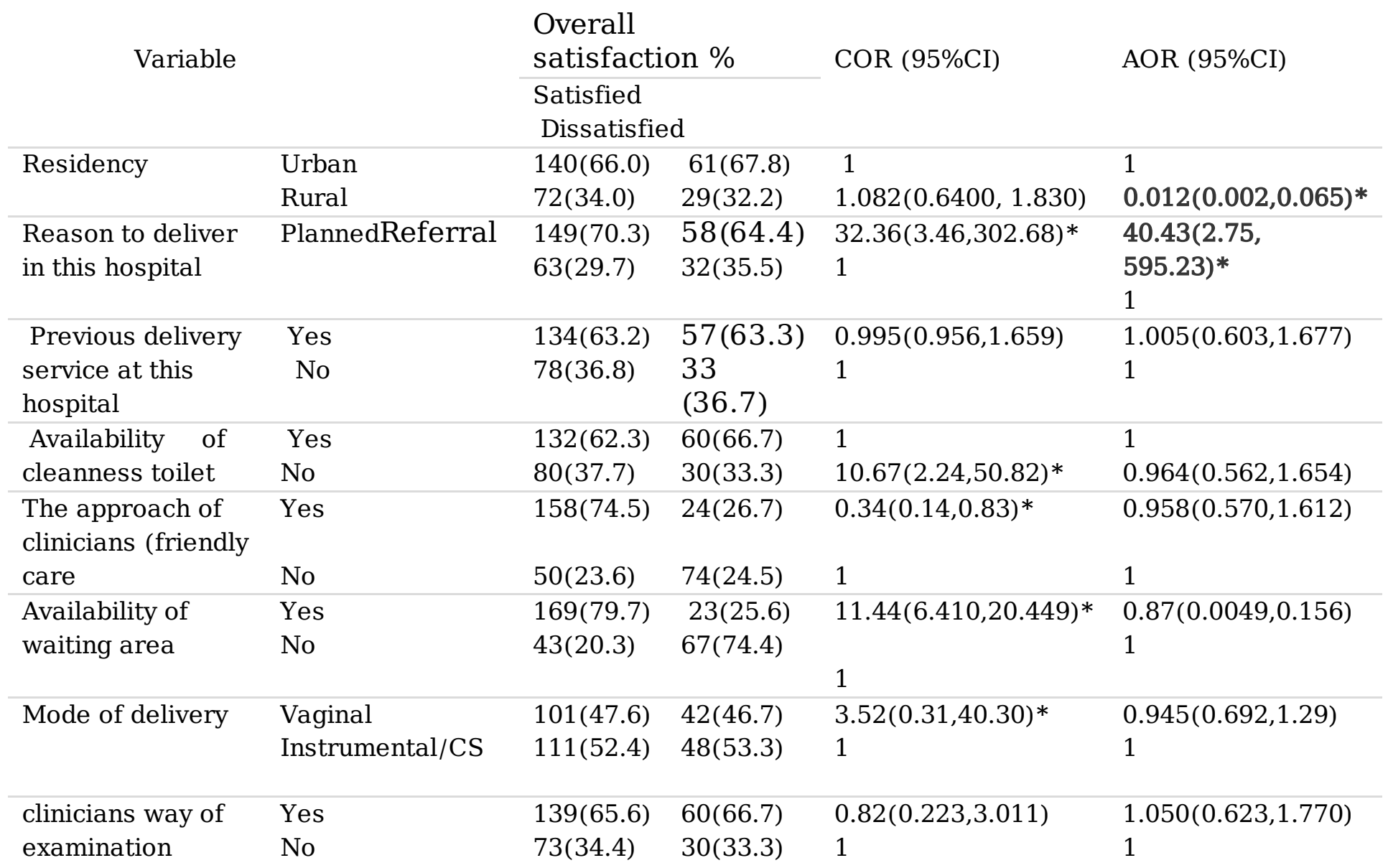

P-value $<0.05 *$ indicate association 